ÉGYPTE monde arabe

\section{Égypte/Monde arabe}

$21 \mid 1995$

Économie égyptienne et perspectives de paix au Proche-Orient

\title{
La libéralisation du secteur agricole
}

\section{Mahmûd Al-Sayyid Mansûr}

\section{(2) OpenEdition}

Journals

Édition électronique

URL : https://journals.openedition.org/ema/406

DOI : 10.4000/ema.406

ISSN : 2090-7273

Éditeur

CEDEJ - Centre d'études et de documentation économiques juridiques et sociales

Édition imprimée

Date de publication : 31 mars 1995

Pagination : 174-182

ISSN : 1110-5097

Référence électronique

Mahmûd Al-Sayyid Mansûr, «La libéralisation du secteur agricole », Égypte/Monde arabe [En ligne], 21 | 1995, mis en ligne le 08 juillet 2008, consulté le 07 juillet 2022. URL : http://journals.openedition.org/ ema/406 ; DOI : https://doi.org/10.4000/ema.406

Ce document a été généré automatiquement le 7 juillet 2022

Tous droits réservés 


\title{
La libéralisation du secteur agricole
}

\author{
Mahmûd Al-Sayyid Mansûr
}

\section{NOTE DE L'ÉDITEUR}

Traduit de l'arabe par Samia Rizq

1 L'agriculture, selon le dernier recensement de 1991/92, fournit 19,2\% du PIB et emploie 4,5 millions de personnes, soit 32,7\% de la population active de l'Égypte. Source principale de l'alimentation, elle assure $20,3 \%$ des recettes d'exportation et produit une part importante des intrants industriels. Conforme à la philosophie de la libéralisation en cours, la stratégie de développement de l'Égypte doit tenir compte des spécificités de son agriculture. Dans les années 60 , la politique agricole était sous le contrôle de la planification centrale, l'État intervenant dans la production, la commercialisation et la fixation des prix de toutes les denrées. Avec l'ouverture économique engagée au milieu des années 70, puis la réforme poursuivie dans les années 80 , le rôle du secteur privé s'est accru. Et avec la libéralisation économique mise en œuvre depuis le début des années 90, l'État place le développement agricole sous le signe de la privatisation, de la libéralisation et du marché.

2 Aujourd'hui, les principaux obstacles au développement agricole sont la réduction de la superficie cultivable par habitant $\mathrm{du}$ fait de la croissance démographique, le morcellement des exploitations, le manque de main-d'œuvre et sa cherté, le risque de pénurie d'eau et la baisse relative de l'investissement. Ainsi, les parts par habitant de terres cultivées et récoltées ${ }^{1}$ ont diminué respectivement de 0,23 à 0,12 feddan ( 1 feddan = 0,42 hectare) et de 0,4 à 0,22 feddan entre 1960 et 1990. Il existe pourtant des possibilités d'extension des superficies cultivées dans la vallée, comme sur les sols désertiques propres à la bonification. Alors que la superficie moyenne des exploitations ne dépasse pas 2 feddans, $50 \%$ des agriculteurs travaillent sur moins d'un feddan. Ce morcellement excessif entrave la mécanisation et l'utilisation des technologies modernes, accroît les coûts de production et favorise la production destinée à l'autoconsommation au détriment du marché local et de l'exportation. 
3 Les changements sociaux, économiques et culturels survenus dans la campagne égyptienne ont réduit l'offre de main-d'œuvre agricole, tandis qu'augmente le chômage parmi les diplômés ruraux ${ }^{2}$. Les ressources totales en eau de l'Égypte, provenant directement du Nil, retraitées ou souterraines, sont estimées en 1990 à 60 milliards de $\mathrm{m}^{3}$, alors que les besoins du pays s'élèveraient à 72,7 milliards de $\mathrm{m}^{3}$ en l'an 2000. La pénurie qui menace l'Égypte impose une stratégie de développement agricole économisant l'eau, par le choix des investissements, des cultures et techniques appropriées ainsi que par l'amélioration des systèmes d'irrigation et de drainage. Or, la part de l'agriculture et de l'irrigation dans la FBFC nationale (formation brute de capital fixe) a baissé par rapport à la période 1981-86, où elle atteignait $10 \%$. Cette proportion, qui n'est plus aujourd'hui que de $7,27 \%$, est en tout état de cause insuffisante par rapport au poids de l'agriculture, tant dans le PIB que dans les exportations ou l'emploi.

4 La politique de libéralisation économique de l'agriculture égyptienne vise à assurer l'utilisation optimale des ressources agricoles (terres, eau, hommes et capital) et à rétablir une juste répartition du revenu national entre l'agriculture et les autres branches. La libéralisation est progressive afin d'éviter les réactions sociales violentes que pourrait éventuellement provoquer un passage trop brusque du système planifié à celui du marché dans les domaines tarifaires, commerciaux et du crédit. Depuis la moitié des années 80 , le gouvernement relève progressivement les prix des produits agricoles sur la base des équivalents internationaux des mêmes produits. En 1987, il a supprimé la vente obligatoire à l'État et totalement libéré les prix de deux cultures de grande consommation (blé et fèves) et de cultures moins stratégiques (sésame, lentilles, arachides, soja. oignons). En 1991, ce fut au tour du riz de voir son prix et sa commercialisation laissés au marché. La libéralisation de la tarification et la commercialisation du coton, principale culture d'exportation, suivra l'achèvement de celle de son commerce extérieur en 1996; la canne à sucre; intrant industriel stratégique pour les raffineries de Haute-Égypte, restera sous le contrôle de l'État.

5 La politique de subvention aux intrants et au crédit agricoles prévalant depuis les années 60 avait pour fonction d'abaisser les coûts de production et de compenser la taxe indirecte résultant de l'imposition aux agriculteurs de prix d'achat inférieurs à la valeur de marché de leurs produits. En relevant progressivement les prix d'achat aux niveaux internationaux, l'État a retiré les subventions aux engrais, semences, pesticides et au fourrage, et remis les taux d'intérêts agricoles au niveau des autres crédits bancaires afin de supprimer les gaspillages inhérents à la sous-évaluation des coûts.

Durant les années 60 et 70, l'État monopolisait l'importation et la distribution des intrants agricoles. Avec la réforme, le secteur privé a été autorisé à participer, à côté des organismes publics, à ces deux activités pour remédier à l'incapacité des firmes publiques à couvrir la totalité des besoins locaux en produits intermédiaires et pour permettre l'accroissement de la production. Avec la libéralisation en cours, la commercialisation des intrants devrait être entièrement privatisée, l'État se réservant la charge de contrôler la

7 qualité des produits importés. Le gouvernement a par ailleurs vendu les terrains et équipements de l'Organisme de bonification des terres désertiques en privilégiant ses locataires et usufruitiers, et favorisé la cession aux particuliers des actifs des entreprises publiques gérées par la loi 203 de 1991. La Banque principale de développement et de crédit agricole (PBDAC en anglais) s'est vue privée de presque 
toutes ses activités d'importation et de distribution des intrants, son rôle étant limité au seul crédit agricole. L'Organisme public de la Caisse de compensation agricole, responsable de la subvention aux prix des intrants agricoles, devrait poursuivre sa mission de soutien à certaines productions, comme ce fut le cas pour le riz et le coton en 1993. L'Organisme public de développement des ressources piscicoles, déchargé de la production, verra son rôle réduit à l'assistance aux producteurs. La valeur du loyer de la terre a été relevée par la loi 96 de 1992. Les fermages contractés avant sa parution et fixés en fonction de la taxe foncière ont vu le multiplicateur de cette dernière augmenter de 7 à 22, pendant une période transitoire s'achevant avec la saison 1996-97. Après cette date, ainsi que pour les contrats conclus au-delà de 1992, les fermages deviennent du ressort du droit civil général qui laisse les loyers et la durée des contrats totalement libres.

\section{Premiers effets globaux de la réforme économique sur l'agriculture}

8 La libéralisation économique est trop récente pour que son impact sur l'agriculture ait pu donner lieu à des études détaillées. Nous nous limiterons donc à l'exposé des données connues concernant la réforme appliquée au cours des années 80 , sachant que les politiques actuelles ne sont que l'approfondissement des mesures engagées depuis près de 15 ans.

Entre 1981 et 1991, le produit agricole a augmenté de 5,4 à 28 milliards de livres égyptiennes (LE) courantes, le revenu de 3,7 à 20,5 milliards LE, les recettes d'exportation de 364 millions à 1,016 milliard LE, tandis que le taux de croissance annuel s'accélérait de 2,6\% en 1981 à 3\% en 1991.

La superficie cultivée et les rendements des principales cultures céréalières (blé, maîs, riz et autres) ont augmenté de telle sorte que leur production globale est passée de 8 à 15 millions de tonnes entre 1981 et 1992. L'augmentation des rendements et des superficies cultivées est due essentiellement aux hausses des prix d'achat des produits aux agriculteurs. Ceci est particulièrement net pour les cultures anciennement contrôlées par l'État (blé, maïs, riz et coton), mais moins évident pour les cultures libres (pommes de terre et agrumes).

11 La relative stabilité de l'indice du prix intérieur du coton entre 1980 et 1992 traduit la volonté de l'État de freiner sa croissance, dont la moyenne annuelle $(6,5 \%)$ suit celle du prix à l'exportation (6\%). L'écart avec ce dernier se creuse néanmoins entre 1988 et 1991, obligeant le gouvernement à relever fortement le prix d'achat du coton en 1989, les agriculteurs délaissant de plus en plus sa culture.

12 Le prix d'achat du riz, seconde culture d'exportation, ne croît que de $2 \%$ par an en moyenne, deux fois moins vite que son prix d'exportation ( $4 \%$ en moyenne annuelle). Le prix intérieur du riz augmente de façon plus significative à partir de 1986 avec la suppression de la livraison obligatoire à l'État et de sa tarification administrative. En conséquence, le rendement à l'hectare de riz s'accroît de 5,5 tonnes en 1987 à 7,6 tonnes en 1992.

13 Le prix intérieur du blé, principal produit agricole d'importation, croît de 5,7\% en moyenne et sa production locale double, passant de 2.017 à 4.483 tonnes entre 1980 et 1991, malgré la baisse de son prix d'importation au taux annuel moyen de $(-3,2 \%)$. La 
libéralisation de la commercialisation du blé a favorisé une croissance des ventes de 88.400 tonnes en 1985 à 173.000 tonnes en 1992. L'autosuffisance en blé s'est élevée de 25\% en 1981 à 45\% en 1992.

Le maïs, seconde culture d'importation, voit sa production croître de 3.347 à 5.122 tonnes de 1982 à 1991.

Les prix intérieurs des pommes de terre et des agrumes, non soumis au contrôle de l'État, fluctuent en fonction des récoltes, la demande locale restant stable.

Les subventions ont également contribué à l'augmentation ou au maintien du volume de certaines cultures. Leur suppression est, avec la libéralisation des prix des produits, un élément fondamental de la réforme économique entamée depuis la fin des années 80.

17 Les subventions aux intrants et au crédit ont en effet favorisé le développement d'entreprises sur des bases non économiques, l'introduction de producteurs inexpérimentés et l'apparition de surcapacités de production. La suppression progressive de ces subventions a permis de réduire le nombre d'entreprises aux établissements les plus compétents.

18 Le montant des aides budgétaires aux produits intermédiaires a ainsi diminué de $11 \%$ par an au cours de la décennie 1980-91. Les prix des semences du coton, du maïs et des pommes de terre sont restées stables pendant cette même décennie, le Ministère de l'Agriculture produisant et distribuant à bas prix les graines dont il voulait encourager l'utilisation. Par contre, les prix des semences de riz et de blé ont crû aux taux annuels moyens respectifs de $13,2 \%$ et $3,6 \%$, du fait de la hausse de leurs prix et de la faiblesse des rendements des semences nouvellement introduites. Les prix des engrais sont restés stables jusqu'en 1990, malgré la baisse de la subvention affectée aux importations de 39 à 13 millions de dollars entre 1980 et 1991. La suppression, à partir de 1991, de cette subvention et des aides à la production locale provoque l'augmentation rapide du prix des engrais. Les subventions aux pesticides sont réduites de 66 à 23 millions de dollars pendant la même décennie, seuls les pesticides du coton restant subventionnés après cette date.

19 Le crédit agricole croît de 549 millions à 1,509 milliard de dollars entre 1980-81 et 1991/92. La PBDAC en assure l'essentiel, mais sa part a diminué de $80 \%$ à 77,5\% entre ces deux années. Les prêts au taux du marché ont remplacé progressivement les prêts subventionnés, puisque leur part dans le total des crédits accordés croît de $6 \%$ à $75 \%$ entre 1985/86 et 1991/92. Les prêts subventionnés concernent les cultures en champs, l'élevage, la bonification des sols désertiques et les machines agricoles. De 1979 à 1987, le taux de crédit aux cultures reste stable à 3,5\%. A partir de la mi-1987, la subvention au crédit est retirée, excepté pour les prêts à certaines activités que l'État cherchait à promouvoir. Les taux d'intérêt bonifiés accordés à ces activités oscillaient, entre 1989 et 1992, de 3,5 à $9 \%$ (pour les plantes oléagineuses, la betterave sucrière et la canne à sucre), de 8 à $11,5 \%$ (pour la bonification\}, de 9 à 14,5\% (pour la sécurité alimentaire ${ }^{3}$ sur les terres désertiques bonifiées), et de 12 à 15,5\% (pour les machines agricoles). En mars 1993, les crédits agricoles subventionnés disparaissent totalement, tandis que la dévaluation de la livre relève les taux d'intérêts libres à un niveau variant entre $17,5 \%$ et $19,5 \%$ pour les céréales, les légumes, la canne et les fruits, à $20 \%$ pour les projets à court terme et $21 \%$ pour les emprunts à moyen terme. 


\section{L'impact de la réforme économique sur le revenu agricole : le cas du blé en Haute-Égypte} techniques qu'économiques, le système des prix étant administré par l'État. Afin de déterminer l'impact du choix de la technique culturale sur le revenu agricole, le Ministère de l'Agriculture a effectué une enquête sur échantillon entre 1982 et 1993, étudiant l'impact du choix de trois techniques de culture sur le revenu du blé en HauteÉgypte. Les trois techniques culturales (traditionnelle, moyenne et avancée) diffèrent par la variété (traditionnelle : «Giza 155 »;améliorée : «Giza 164 ») et la quantité de semences utilisées, par le taux d'application et la nature des engrais ainsi que par le mode d'irrigation des parcelles, les rendements variant de 3,75 à 6,3 tonnes l'hectare.

Selon les résultats de cette enquête, on constate que si les mesures prises durant la première période de la réforme (1986-89) ont entrainé, à l'avantage du producteur, le relèvement de $40 \%$ du prix de vente du blé, elles ont causé, à son désavantage, l'augmentation du coût réel des engrais subventionnés, une hausse de $95 \%$ du coût des semences et une diminution du prix réel libre de la paille. De ces tendances contraires, il a néanmoins résulté une hausse du revenu net réel, d'autant plus importante que la technique choisie était plus avancée.

Dans la seconde phase de la réforme (1990-93), le prix libre du blé a cessé d'augmenter tandis que celui de la paille continuait de baisser; dans le même temps, le coût des engrais et des semences a augmenté de $15 \%$ à $97 \%$, selon les produits, du fait de la suppression des subventions. De ce fait, le revenu net réel a diminué, plus nettement pour les techniques avancées que pour la technique traditionnelle.

II n'en reste pas moins que sur l'ensemble de la période (1982-93), la libéralisation des prix s'est traduite par une hausse du revenu réel. De même, l'augmentation de revenu résultant de la substitution de la technique moyenne à la technique traditionnelle et de la substitution de la technique avancée à la technique moyenne passe, entre 1982 et 1993, de $239 \%$ à $350 \%$ pour la, première substitution et de $256 \%$ à $338 \%$ pour la seconde. La réforme économique a donc incité les producteurs de blé à adopter des technologies plus avancées. Ces variations de prix ont accompagné les réformes institutionnelles que sont la suppression, à partir de 1986, des assolements et de la vente obligatoire à l'État des récoltes, la libéralisation, en 1987, de la commercialisation intérieure du blé, la hausse, dès 1988, des prix courants de détail des engrais, le doublement, en 1991, du prix de la farine et du pain et la suppression, à partir de 1991, de toutes les subventions en application de l'accord signé avec le FMI.

\section{ANNEXES}

Tableau 1 : Indices des prix d'achat au producteur (A) et ratio prix d'achat/prix d'exportation (B) de 1980 à 1992 (US dollar/tonne) 


\begin{tabular}{|c|c|c|c|c|c|c|c|c|c|c|c|c|}
\hline & \multicolumn{2}{|c|}{ Coton } & \multicolumn{2}{|l|}{ Riz } & \multicolumn{2}{|c|}{ Pomme de terre } & \multicolumn{2}{|c|}{ Agrumes } & \multicolumn{2}{|l|}{ Blé } & \multicolumn{2}{|c|}{ Maïs } \\
\hline & A & B & A & B & A & B & A & B & A & B & A & B \\
\hline 1980 & 100 & 52 & 100 & 45 & 100 & 41 & 100 & 25 & 100 & 54 & 100 & 84 \\
\hline 1981 & 100 & 49 & 109 & 38 & 101 & 35 & 95 & 21 & 93 & 41 & 68 & 40 \\
\hline 1982 & 77 & 38 & 130 & 56 & 101 & 33 & 97 & 23 & 75 & 37 & 82 & 54 \\
\hline 1983 & 82 & 43 & 114 & 50 & 103 & 43 & 87 & 16 & 92 & 51 & 101 & 100 \\
\hline 1984 & 108 & 54 & 112 & 57 & 111 & 29 & 140 & 27 & 99 & 53 & 100 & 70 \\
\hline 1985 & 115 & 66 & 122 & 61 & 79 & 33 & 115 & 20 & 93 & 48 & 76 & 72 \\
\hline 1986 & 117 & 74 & 127 & 51 & 70 & 32 & 129 & 20 & 110 & 62 & 76 & 94 \\
\hline 1987 & 81 & 47 & 96 & 56 & 121 & 38 & 141 & 13 & 99 & 60 & 81 & 136 \\
\hline 1988 & 139 & 65 & 112 & 66 & 105 & 27 & 170 & 30 & 101 & 48 & 98 & 62 \\
\hline 1989 & 182 & 70 & 137 & 88 & 106 & 56 & 162 & 32 & 163 & 67 & 108 & 106 \\
\hline 1990 & 183 & 54 & 142 & 96 & 112 & 63 & 163 & 43 & 174 & 109 & 112 & 124 \\
\hline 1991 & 181 & 55 & 135 & 86 & 100 & 42 & 100 & 23 & 145 & 127 & 91 & 99 \\
\hline 1992 & 131 & 31 & 140 & 74 & 81 & 37 & 108 & 31 & 154 & 117 & 90 & 106 \\
\hline
\end{tabular}

Source : calculé par l'auteur d'après les données de la Direction centrale de l'économie agricole et du TradeYear Book, FAO. L'auteur a choisi d'exprimer les prix en dollar US pour éviter les variations dues aux dévaluations par paliers de la livre (NDLR).

Tableau 2 : Indices et ratio subventions agricoles/subvention totale

\begin{tabular}{|l|l|l|l|l|l|}
\hline Année & $\begin{array}{l}\text { Subvention totale } \\
\text { (millions \$) }\end{array}$ & $\begin{array}{l}\text { Indice } \\
\text { subvention } \\
\text { totale }\end{array}$ & $\begin{array}{l}\text { Subvention } \\
\text { agricole (millions } \\
\$ \text { ) }\end{array}$ & $\begin{array}{l}\text { Indice } \\
\text { subvention } \\
\text { agricole }\end{array}$ & $\begin{array}{l}\text { Ratio subvention } \\
\text { Agricole/ subvention } \\
\text { Totale }\end{array}$ \\
\hline 1980 & 1.839 & 100,0 & 202 & 100,0 & $11 \%$ \\
\hline 1981 & 2.105 & 114,5 & 258 & 127,7 & $12 \%$ \\
\hline 1982 & 1.943 & 105,7 & 267 & 132,2 & $14 \%$ \\
\hline 1983 & 1.466 & 79,7 & 183 & 90,6 & $12 \%$ \\
\hline 1984 & 1.715 & 93.3 & 178 & 88,1 & $10 \%$ \\
\hline 1985 & 1.121 & 61.0 & 117 & 57,9 & $10 \%$ \\
\hline
\end{tabular}




\begin{tabular}{|l|l|l|l|l|l|}
\hline 1986 & 882 & 48,0 & 99 & 49.0 & $11 \%$ \\
\hline 1987 & 757 & 41,2 & 94 & 46,5 & $12 \%$ \\
\hline 1988 & 989 & 53,8 & 114 & 56,4 & $12 \%$ \\
\hline 1989 & 1.018 & 55,4 & 98 & 48,5 & $10 \%$ \\
\hline 1990 & 783 & 42,6 & 96 & 47,5 & $12 \%$ \\
\hline 1991 & 390 & 21,2 & 75 & 37,1 & $19 \%$ \\
\hline
\end{tabular}

Tableau 3 : Indices des prix des semences de 1980 à 1991

\begin{tabular}{|c|c|c|c|c|c|}
\hline Année & Coton & Riz & Blé & Maïs & Pommes de terre \\
\hline 1980 & 100 & 100 & 100 & 100 & 100 \\
\hline 1981 & 88 & 98 & 110 & 81 & 104 \\
\hline 1982 & 91 & 113 & 100 & 84 & 94 \\
\hline 1983 & 82 & 136 & 106 & 97 & 61 \\
\hline 1984 & 82 & 149 & 117 & 95 & 66 \\
\hline 1985 & 61 & 116 & 98 & 124 & 45 \\
\hline 1986 & 115 & 127 & 98 & 122 & 42 \\
\hline $1987^{\prime}$ & 103 & 207 & 112 & 77 & 63 \\
\hline 1988 & 103 & 260 & 107 & 86 & 60 \\
\hline 1989 & 91 & 384 & 98 & 97 & 80 \\
\hline 1990 & 91 & 398 & 179 & 118 & 106 \\
\hline 1991 & 76 & 336 & 152 & 100 & 96 \\
\hline
\end{tabular}

Tableau 4 : Indice des prix en dollars US des engrais et pesticides de 1980 à 1991

\begin{tabular}{|l|l|l|l|l|}
\hline Année & Engrais Azotés & Engrais Phosphatés & Potasse & Pesticides \\
\hline \hline 1980 & 100 & 100 & 100 & 100 \\
\hline 1981 & 95 & 100 & 122 & 92 \\
\hline \hline 1982 & 88 & 81 & 102 & 88 \\
\hline
\end{tabular}




\begin{tabular}{|l|l|l|l|l|}
\hline 1983 & 80 & 75 & 94 & 97 \\
\hline 1984 & 80 & 72 & 90 & 79 \\
\hline 1985 & 54 & 50 & 61 & 53 \\
\hline 1986 & 51 & 41 & 55 & 41 \\
\hline 1987 & 76 & 78 & 51 & 55 \\
\hline 1988 & 88 & 53 & 49 & 57 \\
\hline 1989 & 76 & 81 & 43 & 51 \\
\hline 1990 & 171 & 219 & 233 & 74 \\
\hline 1991 & 146 & 178 & 78 & \\
\hline
\end{tabular}

Tableau 5 : Prix constants des produits et intrants du blé (LE constantes, 1982)

\begin{tabular}{|l|l|l|l|l|l|}
\hline & $\begin{array}{l}1982-85 \\
\text { (LE constantes } \\
1982)\end{array}$ & $\begin{array}{l}1986-89 \\
\text { (LE constantes } \\
1982)\end{array}$ & $\begin{array}{l}1990-93 \\
\text { (LE constantes } \\
1982)\end{array}$ & $\begin{array}{l}\text { Variation } \\
1982-85 / 86-89\end{array}$ & $\begin{array}{l}\text { Variation } \\
1986-90 / 90-93\end{array}$ \\
\hline Graines 400\% & 95,6 & 136.3 & 137.5 & $43 \%$ & $1 \%$ \\
\hline Paille 44\% & 16.9 & 12.9 & 6.5 & $-24 \%$ & $-50 \%$. \\
\hline Semences & 140.0 & 274,0 & 316,0 & $96 \%$ & $15 \%$ \\
\hline Urée 46,5\% & 100.0 & 80,7 & 103,0 & $-19 \%$ & $28 \%$ \\
\hline $\begin{array}{l}\text { Nitrate amonia } \\
33.5 \%\end{array}$ & 71,8 & 54,1 & 77,6 & $-25 \%$ & $43 \%$ \\
\hline $\begin{array}{l}\text { Superphosphate } \\
15 \%\end{array}$ & 24,2 & 20,1 & 39.6 & $-17 \%$ & $97 \%$ \\
\hline Malathione & 1,9 & 3.2 & 2,8 & $68 \%$ & $-13 \%$ \\
\hline
\end{tabular}

Source : A.W. Hassan. Aden A., Mansûr M. et alii, Impact of Technology and Prices Policies on Profitabifity of Wheat in Upper Egypt, May 29 - June 2, 1994. Cairo.

Tableau 6 : Coût et revenu du blé selon la technologie utilisée 


\begin{tabular}{|c|c|c|c|c|c|c|c|c|c|}
\hline $\begin{array}{l}\text { Technologie / } \\
\text { période }\end{array}$ & $\begin{array}{l}\text { Coût et } \\
\text { Revenu }\end{array}$ & & $\begin{array}{l}982-85 \\
\text { E } \\
\text { onstar } \\
982)\end{array}$ & 5 & & $\begin{array}{l}\text { 86-89 } \\
\text { E nstantes } \\
82)\end{array}$ & $\begin{array}{l}1990-93 \\
(\mathrm{LE} \\
\text { constantes } \\
1982)\end{array}$ & $\begin{array}{l}\text { Variation } \\
1982-85 / \\
86-89\end{array}$ & $\begin{array}{l}\text { Variation } \\
1986-90 / \\
90-93\end{array}$ \\
\hline \multirow[t]{2}{*}{ Traditionnelle } & Coût & 490 & 417 & 304 & $-73 \%$ & $-113 \%$ & & & \\
\hline & Revenu & 216 & 363 & 350 & $147 \%$ & $-13 \%$ & & & \\
\hline \multirow[t]{2}{*}{ Médiane } & Coût & 558 & 473 & 346 & $-85 \%$ & $-127 \%$ & & & \\
\hline & Revenu & 408 & 594 & 549 & $186 \%$ & $-45 \%$ & & & \\
\hline \multirow[t]{2}{*}{ Avancée } & Coût & 620 & 527 & 392 & $-93 \%$ & $-135 \%$ & & & \\
\hline & Revenu & 556 & 772 & 698 & $216 \%$ & $-74 \%$ & & & \\
\hline \multirow{2}{*}{$\begin{array}{l}\text { Moyenne } \\
\text { Nationale }\end{array}$} & Coût & 363 & 379 & 339 & $16 \%$ & $-40 \%$ & & & \\
\hline & Revenu & 351 & 548 & 565 & $197 \%$ & $17 \%$ & & & \\
\hline
\end{tabular}

Source: A.W. Hassan, Aden A., Mansûr M. et a/H. Impact on Technology and Prices Policies on Profitability of Wheat in Upper Egypt, May 29 - June 2, 1994, Cairo.

\section{NOTES}

1. Grâce à l'irrigation pérenne et au climal, les sols supportent deux à trois cultures par an, sans jachère (NDLR).

2. Voir l'article de Mûsa 'Abd al-Azîm dans ce même dossier.

3. La « sécurité alimentaire " désigne les cultures et l'élevage de produits de substitution aux importations. Ils sont considérés «stratégiques ", parce qu'ils apportent des devises à la balance des paiements, fournissent des revenus aux agriculteurs, et des produits alimentaires à bas prix aux consommateurs. Ces produits bénéficient de nombreux avantages et dérogations, et ne sont pas soumis à la commercialisation et à la tarification étatiques.

\section{INDEX}

Mots-clés : libéralisation, agriculture 
AUTEUR

MAHMÛD AL-SAYYID MANSÛR

Ministère de l'Agriculture 